\title{
Violence Against Children at Home and Family in Kosovo Society. the Prevalence, Types and Perpetrators of Violence
}

\author{
Armen Mustafa, PhD Cand. \\ Probation, Service of Kosovo, Ministry of Justice, Pristina, Kosovo
}

\begin{abstract}
The main purpose of this study was to study the level of violence against children in the family and home, types of violence, and perpetrators. This study is based on the study of a sample of 618 children grades 10-12, from high schools of Pristina. The sample was subjected to a questionnaire, made up of 4 questions for each type of violence: neglect, psychological violence, physical violence and sexual violence. The results of this study show that during their lifetime, nearly $30 \%$ of children at least once felt neglected, over $44 \%$ at least once have experienced psychological violence, $35 \%$ physical violence and $11 \%$ sexual violence. Mostly children experience violence in the home and family, by people who are not part of the immediate family (19.7\%), followed by parents (18. $6 \%$ ) and siblings (10.7\%). Girls experienced more neglect and psychological violence, while boys more physical and sexual violence. Neglect and sexual violence against children are expressed more in urban environments, while physical and psychological violence more in rural areas. The data shows that children more experience violence from family members of the same sex. Fathers and brothers are those who practice more violence against boys, while mothers and sisters more to girls.
\end{abstract}

Keywords: Violence, neglect, psychological violence, sexual violence, physical violence

\section{Introduction}

Kosovo for a long time has passed through a long phase of violence that violence has escalated, especially in the 90s under Serb occupation, where psychological and physical violence was almost an everyday life. The violence peak will be armed war during 1998 - 1999 years, in that period will be carried even the harshest and most brutal human behavior, such as rape and numerous massacres to the extent of genocide against the Kosovo Albanian population.

End of war and structured Serb violence in Kosovo, in fact does not mean the violence completion and anti-social behavior in our society. Many problems that will characterize our society in the postwar period, as political (political uncertainty status, lack and law breakdown etc.), economic (not economic development) and social (poverty, unemployment, lack of prospects etc.), along with the consequences of war (many murders, the disappearance of many people, many destructions, large number of weapons in the hands of the population, trauma, etc.), resulted in actuality today that largely characterizes the phenomenon of violence, a phenomenon which is widespread in almost all segments of society, starting from the family as the foundation of our society to continue in school and educational institutions and society in general.

From this social context even children of all ages in general were not excluded. They have now become the object of violence by parents, teachers, peers, but also the society in general (KAS, 2014; UNICEF, 2005). Using violence against them wherever they are, in families, at school, in the streets, in the neighborhood, by other words everywhere.

\section{Literature review}

Family is the first environment, the environment where are created experiences the first social reports with close people, primarily with parents or caretakers, and then with other family members. Since the family is of vital importance for the child, the violence experience in this environment, growth and child's development in such conditions resulting in the most serious consequences for their child's development 
If we refer to the United Nations report on violence against children, the report violence against children in the family treats it dividing into four types of violence, physical violence, neglect, sexual and psychological violence (Pinheiro, 2006). According to the report, physical violence is the most widespread form of violence against children compared to other types of violence against children in the family. Kicking, punching, hair pulling, shaking, pinching are some of the violent behavior that most children suffer violence. Parents are considered the most common physical violence perpetrators. But other members as brothers and sisters, grandparents, uncles, aunts often do physical violence at home (Party, Unalacak., Unluoglu, 2011). Even brothers and sisters physical violence in the family could to be the most frequent violence comparing with parents violence itself (Olive, Collins, \& Levitt, 2007).

On the other hand neglect is considered one of the most difficult forms to interpret, especially in poverty conditions. However, in developed countries, the neglect is regarded as one of the most common forms of abused children in the family (Hussey, Chang \& Kotch (2006). There are children under age who neglected the most (Olive, Collins \& Levi, 2007; Pala, Unalacak \& Unlouglu, 2011).

According to the World Health Organization is estimated that around 150 million girls and 73 million boys under 18 have suffered forced sexual intercourse or other sexual violence involving physical contact (Pinheiro, 2006, p. 55). However, in general violence and sexual abuse of children in the family is less widespread than other forms of violence.

From the total number of abused children, only $10 \%$ are considered to be sexually abused. Males' dominated age of the sexual abuse is 4-6 years, while women 11-14 (Olive, Collins \& Levi, 2007. p. 78). A large number of violence cases is practiced by family members or close family persons, such as: parents, stepfathers, caretakers, aunts, uncles, siblings, grandparents, cousins and family friends (Pinheiro 2006).

All physical and sexual violence forms among other also cause psychological damage, but psychological violence can take specific forms, such as insults, calling different names, humiliation, isolation, ignorance, intimidation, etc. Thus, according to a survey conducted in 5 countries (Chile, Egypt, India, the Philippines and the US), yelling and roaring against children were punishment practices for children by parents in all 5 countries (Pinheiro, 2006, p . 62). The family and its structure, as factors with significant impact on violence against children in the family have been the subject of many research studies conducted by different researchers. According to these studies, children are generally victimized mostly by different persons outside the family, then the family members (Turner, Finkelhor \& Ormrod, 2007; Savolainen, 2007). Against girls usually exerted low-level violence, unlike the boys against whom violence is serious (Sariola \& Uutela, 1992)

\section{Methodology}

The data in this study come from PhD study about violence against children in society. The purpose of the research is to study the violence prevalence against children in the family and home, types and violence perpetrators against children. The study is based on quantitative methodology, in a sample of 618 students with 10-12 grades who come from Pristina secondary schools (Tab.1). Sample selection was based on probability method of simple random sampling, based on $95 \%$ of the confidence level and the $5 \%$ of margin error. In the sample was administered a questionnaire, based on obtaining of the students' experiences about violence in home and family, through self-reporting. The questionnaire includes closed type questions, where subjects choose one of the options that best fit about their experiences ,regarding violence specifically, divided into 4 parts: neglect (lack of food, hygiene, support, protection in risk cases and lack of health care), psychological violence (insults, ridicule, use of names contemptuous, holding anger, threats and intimidation, verbal threats or intimidation on use of weapons), physical violence (hitting, kicking, hair pulling, assault with use of solid objects or weapons) and sexual violence (harassment and verbal concerns about child sexuality such as touch the body or intimate part of children without his / her desire .moreover forcing to have or watch sexual things, and sexual purpose attacks, attempted or sexual rape).

This division is based on the United Nations report on violence against children (Pinheiro, 2006). For each form of violence, are raised by 4 questions, those questions actually describe a specific type of violent behavior that children, students could have experienced during their childhood. Also, students were asked for people who mostly use violence against them in family and home. Before the questionnaire administered, subjects were initially informed about the purpose, and is consented from subjects and institutions where questionnaire is administered (schools). The administration of the 
questionnaire was made in a period of 40 minutes, after that the data from the questionnaires were entered and analyzed by SPSS 22.

Tab. 1. Demography Characteristics of participants

\begin{tabular}{|c|c|c|}
\hline Sample & $\mathrm{N} / \%$ & Total \\
\hline Age & & 618 \\
\hline 15 years & $75 / 12.1$ & \\
\hline 16 years & $179 / 29.0$ & \\
\hline 17 years & $178 / 28.8$ & \\
\hline 18 years & $176 / 28.5$ & \\
\hline Other & $10 / 1.6$ & \\
\hline Gender & & 618 \\
\hline Female & $315 / 51.0$ & \\
\hline Male & $303 / 49.0$ & \\
\hline Urban - rural & & 618 \\
\hline Urban & 486 / 78.6 & \\
\hline Rural & $132 / 21.4$ & \\
\hline
\end{tabular}

\section{Results}

Study data about violence against children in the family and home, shows that the most widespread form of violence against children in the family is psychological then physical violence, neglect and sexual violence end (Table 2).

So, 263 or $43.5 \%$ of students have experienced psychological violence at least once during their lives. Of these, 207 or $34.2 \%$ have experienced psychological low-level violence up to average, 43 or $7.1 \%$ of psychological violence was from average level to the high-level and 13 or $2.3 \%$ of psychological violence was from high level to the extreme.

213 or $34.7 \%$ of students have experienced physical violence at least once in their lifetime. Of these, 117 or $28.9 \%$ have experienced violence from low-level to average-level, 23 or $3.7 \%$ physical violence from average level to high-level and 13 or $2.1 \%$ of students have experienced violence from the high-level to the extreme level.

Different types of neglect, at least once in their lives have experienced 179 or $29.5 \%$ of students, where 149 or $24.6 \%$ have been neglected up to average-level, 23 or $3.8 \%$ have been neglected from average-level to high-level and only 7 or $1.2 \%$ of students felt neglected in extreme level.

The type of violence that is in smaller prevalence is sexual violence against children. The results show that 68 students or $11.1 \%$ have experienced sexual violence in family and home at least once. Of these 460 se $7.5 \%$ have experienced sexual violence up to the average, 23 or 3.7 of the average level up to high-level and 12 or $2 \%$ have experienced sexual violence to an extreme level. 
Tab. 2 Prevalence and types of violence in total and according to gender of participants

\begin{tabular}{|l|l|l|l|l|l|}
\hline & $\begin{array}{l}\text { None } \\
\mathrm{N} / \%\end{array}$ & $\begin{array}{l}\text { Low to } \\
\text { moderate } \\
\mathrm{N} / \%\end{array}$ & $\begin{array}{l}\text { Moderate to } \\
\text { severe } \\
\mathrm{N} / \%\end{array}$ & $\begin{array}{l}\text { Severe to } \\
\text { extreme } \\
\mathrm{N} / \%\end{array}$ & $\begin{array}{l}\text { Total } \\
\mathrm{N} / \%\end{array}$ \\
\hline Neglect & $428 / 70.5$ & $149 / 24.6$ & $23 / 3.8$ & $7 / 1.2$ & $607 / 100$ \\
Female & $212 / 67.9$ & $84 / 27.0$ & $12 / 3.8$ & $4 / 1.3$ & $312 / 51.4$ \\
Male & $216 / 73.6$ & $65 / 22.1$ & $11 / 3.8$ & $3 / 0.9$ & $295 / 48.6$ \\
Psychological Violence & $342 / 56.5$ & $207 / 34.2$ & $43 / 7.1$ & $13 / 2.3$ & $605 / 100$ \\
Female & $170 / 54.8$ & $104 / 33.6$ & $25 / 8.0$ & $11 / 3.5$ & $310 / 51.2$ \\
Male & $142 / 58.3$ & $103 / 34.9$ & $18 / 6.1$ & $2 / 0.6$ & $295 / 48.8$ \\
Physical violence & $401 / 65.3$ & $177 / 28.9$ & $23 / 3.7$ & $13 / 2.1$ & $614 / 100$ \\
Female & $217 / 69.1$ & $81 / 25.8$ & $9 / 2.9$ & $7 / 2.2$ & $314 / 51.1$ \\
Male & $184 / 61.3$ & $96 / 32.0$ & $14 / 4.6$ & $6 / 1.9$ & $300 / 48.9$ \\
Sexual Violence & $544 / 88.9$ & $46 / 7.5$ & $10 / 1.6$ & $12 / 2.0$ & $612 / 100$ \\
Female & $288 / 91.4$ & $20 / 6.4$ & $3 / 0.9$ & $4 / 1.2$ & $315 / 51.5$ \\
Male & $256 / 86.2$ & $26 / 8.7$ & $7 / 2.3$ & $8 / 2.6$ & $297 / 48.5$ \\
& & & & & \\
\hline
\end{tabular}

Viewed by gender aspect (Table 2), girls reporting that they have been more neglected in comparison with boys, beginning from the lowest level to the highest level of neglect. $32.1 \%$ of girls reported that during their lifetime felt neglected at least once, while $5.1 \%$ felt at a level over the average to the extreme, opposed of boys who $26.4 \%$ felt at least once neglected, and $4.7 \%$ have been neglected from the average level to the extreme. However, this difference is not of statistical significant.

Also to psychological violence are girls those who reported that they have experienced psychological violence more, or $45.2 \%$ of them, in contrast to boys who reported at $41.7 \%$. However, the boys reported having experienced violence a little more of low-level than girls (34.9\% vs. $33.6 \%$ ), while the average level to the extreme are girls those who have experienced more than boys ( $11.5 \%$ vs. $6.7 \%$ ). These differences between girls and boys are not with statistical significant. There are no differences of statistical significance as regards to the physical violence. Generally there are boys who have experienced more physical violence than girls ( $38.7 \%$ vs. $30.9 \%)$, with the only difference that the girls have experienced above average and extreme level of violence compared with boys ((2.2\% vs. $1.9 \%)$.

However, the differences are significant in statistical aspect when we are talking about sexual violence $(P<0.05$ level). The boys are reporting that they have experienced more sexual violence in the family and home, compared to the girls (13.8\% vs. $8 \%$ ). This difference is at all levels of violence experienced.

On the other hand the differences concerning urban - rural aspect are students those who come from urban areas who have reported more neglect and sexual violence experienced, compared to students from rural areas who report more physical and psychological violence experience (graph.1). But none of these differences are not with statistical significant. 


\section{Graph.1 The prevalence and types of violence based on the participants' residence (urban - rural)}

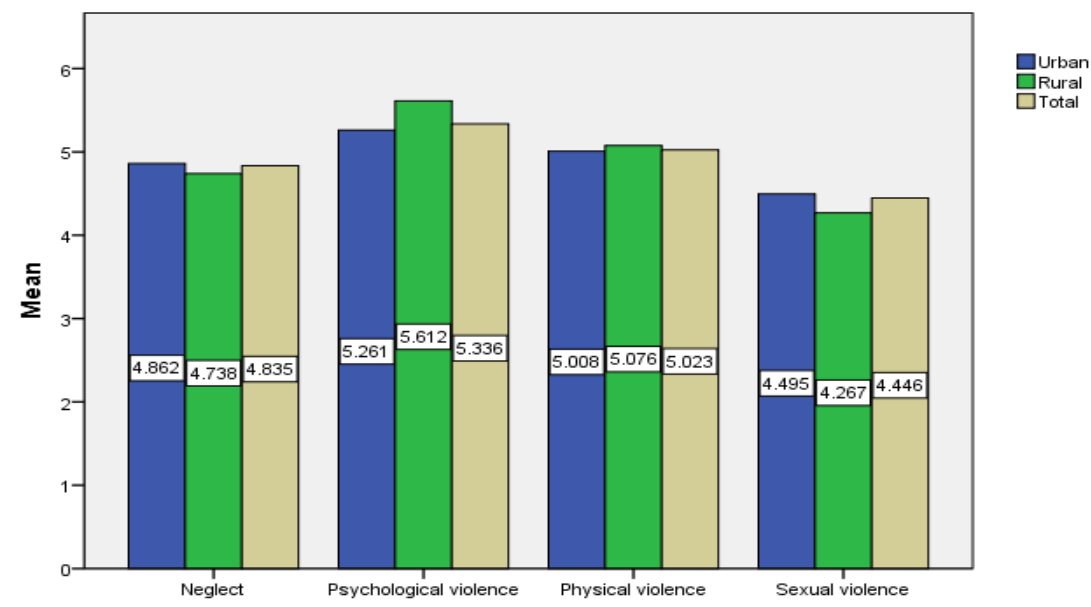

Tab.3 Perpetrators of violence against children in the family and home

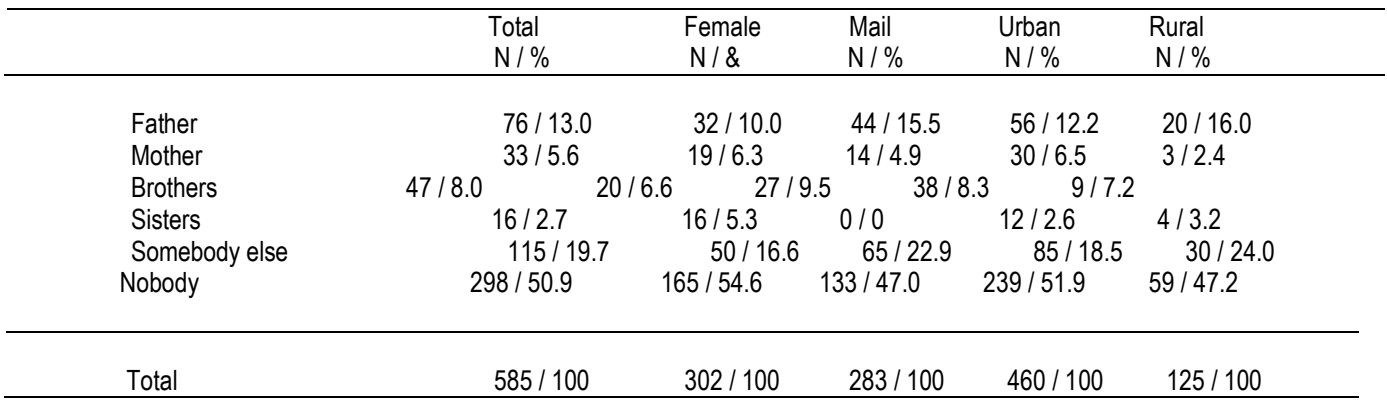

The most frequent perpetrators of violence against children in the family and home are usually people who are not part of the immediate family (Tab.3). From the total sample, $19.7 \%$ of them reported that the most frequent violence perpetrators in family and home are not members from immediate family (father, mother, brother, sister). From immediate family, the most often perpetrator are fathers $(13 \%)$, after them brothers $(8 \%)$, then mothers $(5.6 \%)$ and at the end sisters $(2.7 \%)$. When we are to violence perpetrators against children in family, there are gender differences with regard to the perpetrators gender, as well gender of those who have experienced violence. Perpetrators from outside the immediate family use more violence against boys than the girls in general $(22.9 \%$ vs. $19.7 \%)$. Fathers seem to practice more violence against boys than the girls ( $15.5 \%$ vs. $10 \%)$, while mothers practice violence against girls more than boys ( $6.3 \%$ vs. $4.9 \%)$. This violence against same gender appears also to brothers and sisters. Brothers use more violence against boys than girls ( $19.5 \%$ vs. $6.6 \%)$, while the sisters have been reported to have used more violence against girls only (5.3\%), but not against boys ( 0 $\%)$.

There are also differences in residence terms (urban - rural) of the study subjects. Even here, most perpetrators are persons who are not part of the immediate family, with a difference that these people are reported more from students coming from rural areas ( $24 \%$ vs. $18.5 \%)$. According to these data, the fathers from rural areas use violence against their children more than those from urban areas (16\% vs.12.2\%), while mothers from urban areas use violence against their children more than those from rural areas ( $6.5 \%$ vs. $2.4 \%)$. Brothers as perpetrators were more reported by students who come from urban areas than those from rural areas ( $8.3 \%$ vs. $7.2 \%)$, while the sisters have more reported as perpetrators from students who come from rural areas than those from urban areas (3. $2 \%$ vs. $2.6 \%$ ). 


\section{Discussions and conclusions}

The results of this study show that Violence against children in the home and family is widespread in Kosovo society. According to the Report of the United Nations (Pinheiro, 2006), physical violence is more prevalent than other types of violence, while in Kosovo it seems that psychological violence is more prevalent $(43.5 \%$ have experienced at least once, and about $10 \%$ went to levels above the average). However, when we are at this level of psychological violence, this somehow confirms the fact that psychological violence is experienced whenever there are other types of violence. But also it can take special forms like insults, social isolation, harassment and intimidation, especially in parenting practices of punishment for children by parents (Pinheiro, 2006).

On the other hand, in Kosovo, the prevalence of physical violence against children in the family it is quite high ( $34.7 \%$ of students have experienced at least once physical violence in family and approximately $6 \%$ have experienced violence above average level).

While, neglect which is considered as one of more prevalent types of violence against children in families in developed countries, in Kosovo is less prevalent than psychological violence and physical violence (approximately $30 \%$ of students felt at least once neglected and $5 \%$ felt neglected above the average). This can be explained by the fact that in poverty conditions, what is considered to be neglected is difficult to interpret (Pinheiro, 2006). In this regard, Kosovo is not part of the industrially developed countries, and poverty in Kosovo is in the level of $30 \%$ of the population, while extreme poverty is $10 \%$ of the population (KAS, 2013).

The prevalence of sexual violence against children in Kosovo's families and homes are consistent with other studies about this issue (Olive, Collins \& Levi, 2007). However, $10 \%$ of students experienced at least once one of the sexual violence types, and $2 \%$ of students have experienced sexual violence above average level. If we add the fact that overall violence against children, including sexual violence in Kosovo families mostly coming from people outside the immediate family, this indicate that parents, generally do not abuse with their parental responsibilities that they have.

This study also shows that there are no significant gender differences in terms of violence experienced between boys and girls. Girls generally experience more neglect and psychological violence, while boys experience more physical violence and sexual violence. In this sense, the fact that boys experience more sexual violence differs from many other studies, according to which are girls who experience sexual violence more than boys (Radford, L, et al., 2009).

This study highlights that most often perpetrators of violence against children in the family and home are not members of immediate family. This can be explained by the fact that in Kosovo still is tendency to live in large families, composed of more than 2 generations (grandparents, parents, children, aunts and uncles). The most perpetrators from immediate family are fathers who practice violence more often, followed by brothers, mothers and sisters. These findings of the study about perpetrators are in line with the findings from the study in UK "Child Abuse and Neglect" (Radford, L, et al., 2009). When we are talking about members of immediate family, in the study we distinguished "violence against the same sex". Fathers and brothers practice violence more often against boys than girls and vice versa, mothers and sisters use more violence against girls. In rural areas physical and psychological violence against children are more prevalent than in urban areas, where more prevalent are neglect and sexual violence against children in the Kosovo families.

\section{References}

[1] Hussey, J.M., Chang, J.J., Kotch, J.B. (2006). Child Maltreatment in the United States: Prevalence, Risk Factors, and Adolescent Health

[2] Kosovo Agency of Statistics, (2013). Consumption poverty in the Republic of Kosovo in 2011.Pristina

[3] Kosovo Agency of Statistics, (2014).Multiple Indicator Cluster Survey in Republic of Kosovo. 2013-2014, Key Findings. Pristina, Kosovo.

[4] Olive, M. F., Collins, C. and Levitt, P., (2007). Child Abuse and Stress Disordes. New York. Chelsea House. ISBN 07910-9006-X.

[5] Pala, B., Unalacak, M., Unluoglu, I., (2011). Child Maltreatment: Abuse and Neglect. Dicle Tip Dergisi / Dicle Medical Journal. 2011; 
[6] 38(1):121-127.

[7] Pinheiro, P. S., (2006). World Report on Violence against Children. Geneva. Published by the United Nations Secretary-General's

[8] Study on Violence against Children. ISBN-10 92-95057-51-1.

[9] Radford, L, Corral, S., Bradley, C., Fisher, H., Bassett, C., Howat, N. and Collishaw, S. (2009). Child Abuse and Neglect in the UK today.

[10] National Society for the Prevention of Cruelty to Children. London

[11] Sariola, H. \& Uutela, A. (1992). The Prevalence and Context of Family Violence against Children in Finland. Child Buse \& Neglect.

[12] Vol. 16,pp. $823-832$.

[13] Savolainen, J. (2007). Family Structure and Adolescent Victimization in Finland: Investigating the Stepfamily as a Source of Risk.

[14] Research on Finish Society. Vol. 1 (2007), pp. 17 - 27.

[15] Turner, H.A., Finkelhor, D. And Ormorod, R. (2007). Family Structure Variations in Patterns and Predictors of Child Victimization.

[16] UNICEF, (2005). Research into Violence against Children in Schools in Kosovo. Pristina.

[17] American Journal of Orthopsychiatry. 2007, Vol. 77, No.2, 282 - 295.

[18] Consequences. Pediatrics Volume 118, Number 3, September 2006. 